\title{
Inovação Aberta no Setor Público em Minas Gerais Trajetória, Desafios e Possibilidades
}

\author{
http://dx.doi.org/10.21527/2237-6453.2019.48.84-102
}

Recebido em: 6/7/2017

Aceito em: 18/3/2019

\section{Rony Klay Viana de Freitas ${ }^{1}$, Florence Cavalcanti Heber Pedreira de Freitas ${ }^{2}$}

\section{RESUMO}

O artigo analisa uma proposta de inovação aberta na gestão pública criada pelo governo do Estado de Minas Gerais (Brasil), denominada Movimento Minas, com o objetivo de compreender as bases do modelo, sua trajetória, desafios e perspectivas futuras por meio de uma abordagem de pesquisa qualitativa. Associados à tentativa de apropriação do conhecimento social para utilização no processo de inovação na gestão pública, o conceito e as práticas de inovação aberta na experiência analisada não tinham definição clara e o projeto enfrentou diversos problemas de legitimação no interior do governo e na sociedade.

Palavras-chave: Inovação aberta. Administração pública. Projeto Movimento Minas.

\section{OPEN INNOVATION IN THE PUBLIC SECTOR IN MINAS GERAIS:}

TRAJECTORY, CHALLENGES AND POSSIBILITIES

\section{ABSTRACT}

The article analyzes an open innovation proposal in public management created by the government of Minas Gerais (Brazil), called Movement Minas, with the aim of understand the model bases, its trajectory, challenges and perspectives through qualitative research. Associated with the attempt to appropriate social knowledge for use in the innovation process in public management, the concept and the open innovation practices analyzed in the experiment were not clearly defined and the project faced many problems legitimacy within the government and in society.

Keywords: Open innovation. Public administration. Movement Minas Project.

\footnotetext{
${ }^{1}$ Mestre em Administração pela Universidade Federal de Sergipe (UFS). Analista de Planejamento, Gestão e Infraestrutura do Instituto Brasileiro de Geografia e Estatística (IBGE).ronyfreitas@gmail.com

2 Doutora em Administração pela Universidade Federal da Bahia. Professora da Universidade Federal de Sergipe (UFS). florenceheber@hotmail.com
} 
A participação social tornou-se um dos princípios limiares nos processos de concepção e construção de políticas públicas (MILANI, 2008), muito embora as práticas de participação dos cidadãos na formulação dessas políticas, em sua grande maioria, ainda sejam meramente consultivas. Surgem no cenário internacional, todavia, novas propostas para a inserção do cidadão no processo de construção de soluções para os problemas governamentais. Atualmente os cidadãos estão cada vez mais atentos e com maiores possibilidades de obter informações sobre as ações dos governos e seus reflexos na vida em comunidade. Em muitos países, as práticas de participação popular, antes por meio da representatividade em sua maioria, estão se transformando em práticas baseadas nos conceitos de inovação aberta, a exemplo do governo dos Estados Unidos, conforme apresentado por Lukensmeyer, Goldman e Stern (2011).

A definição de inovação, no entanto, tem sido apresentada de forma ampla, difusa e diversa. Além disso, também se verifica uma tendência de ampliação do entendimento do conceito no contexto do setor público (KLERING; ANDRADE, 2006; DAMANPOUR; WALKER; AVELLANEDA, 2009; BOLLIGER, 2014).

A partir da análise da produção científica em periódicos nacionais e internacionais da área de Administração, Brandão e Bruno-Faria (2013) verificaram que os conceitos de inovação no setor público, adotados por diversos autores em artigos científicos, estão relacionados com os já consolidados na literatura sobre inovação no setor privado.

Nesse cenário, com o crescente sucesso de práticas de inovação aberta em organizações privadas, conforme indicado por Chesbrough (2003) e, como essa ideia e prática se expande, tornou-se importante revisitar o que significa o "termo" e levantar a questão abordada especificamente neste estudo, que é a de compreender como esses princípios estão sendo incorporados pelas organizações do setor público.

Essa perspectiva de abordagem foi reforçada pelo estudo de Chiaroni, Chiesa e Frattini (2009), no qual afirmaram que muitas vertentes da inovação aberta ainda precisam de estudos adicionais para que essa temática se consolide.

No que se refere às possibilidades de inovação no setor público, Jordão (2012) argumenta que em contexto de redefinição do papel do Estado, verifica-se também uma redefinição da relação entre o Estado e a sociedade.

Cunha, Coelho e Przeybilovicz (2017) lembra que desde a década de 90 do século 20 diversas iniciativas de governo eletrônico (eGov) foram colocadas em prática no mundo e que essas experiencias tornaram-se um campo atrativo de estudo, ampliando a participação do tema em conferências e periódicos de referência na administração pública.

Ademais, na bibliografia da área existem discussões e teorias sobre a participação da sociedade nas políticas públicas, tais como: formação de conselhos sociais, plataformas de consulta do cidadão, participação da sociedade no orçamento. Este estudo, no entanto, procura ir além dessas possiblidades ao investigar outras formas de atuação do cidadão como protagonista no processo de inovação governamental. De modo geral, propõe uma avaliação das práticas de inovação aberta que, em tese, se apresentam como uma alternativa estratégica de evolução no relacionamento entre o governo e a sociedade. 
Com base nesses pressupostos o artigo é baseado na seguinte questão: De que forma ocorre o processo de inovação aberta na administração pública? Para responder a esse questionamento, inicialmente foi realizada uma pesquisa nos sites dos governos federal e estaduais no Brasil para averiguar a existência de ações e políticas que tiveram como base a inovação aberta.

A partir dessa pesquisa identificou-se o projeto Movimento Minas, idealizado pelo governo de Minas Gerais em 2011, constituindo esta uma experiência inspirada no conceito de inovação aberta e, assim, escolhida como objeto de estudo.

O projeto Movimento Minas foi criado com a proposta de ser um espaço para que os cidadãos, diretamente, proponham ideias para melhorar a vida em sociedade por meio das políticas públicas a serem elaboradas pelo governo. Integrava também o programa "Gestão para a Cidadania" do governo do Estado de Minas Gerais na gestão 2010-2014.

Para entender a formação e trajetória do projeto foi utilizada uma metodologia qualitativa que buscou, especificamente, compreender as bases do modelo de inovação aberta proposto, sua trajetória, experiências, a percepção dos atores envolvidos no processo, os desafios e perspectivas, como será analisado em seguida.

\section{INOVAÇÃO ABERTA NA ADMINISTRAÇÃO PÚBLICA}

O termo "inovação" pode ter diversas acepções dentro do campo da Administração. Outrossim, conforme analisam Klering e Andrade (2006), quando a análise deste "termo" é associada à administração pública, deve-se atentar para uma condição nova de acordo com os pressupostos e suas ações.

A inovação está no alcance de algumas iniciativas postas em prática pelas esferas locais de governo que configuram verdadeiras redes de atores e de entidades mobilizados em torno de um ou mais problemas de interesse público, cujo enfrentamento ultrapassa a capacidade de ação isolada do Estado (JACOBI; PINHO, 2006).

A participação atual dos cidadãos no processo de prestação de serviços, entretanto, é limitada; praticamente pode ser cumprida apenas na fase de avaliação final de um serviço específico. Há poucas providências para envolver os cidadãos (e empresas) em um diálogo bidirecional com as administrações públicas. Na maioria dos casos há uma total ausência de métodos organizados e legalmente suportados para a participação direta dos cidadãos no processo de tomada de decisão (KOKKINAKOS et al., 2012). Em contrapartida, diversos governos de todo o mundo estão considerando adotar abordagens centradas no cidadão e na prestação de serviço público, e esquemas de colaboração em âmbito nacional ou internacional (KOKKINAKOS et al., 2012).

Tal percepção de que atores externos à organização são importantes no processo inovativo empresarial é discutido na literatura desde os trabalhos de Hippel (1988), Cohen e Levinthal (1990) e Lundvall $(1985,1990,2001)$. Em seus estudos, esses autores argumentam que os atores externos à organização são fatores-chave no processo de inovação da empresa.

Chesbrough (2003) avalia que as empresas estão cada vez mais repensando a maneira de lidar com a inovação e estão aproveitando ideias externas nos processos internos. No modelo antigo, de inovação fechada, as empresas geravam suas próprias 
ideias, desenvolviam, fabricavam e distribuíam. A filosofia consistia em: "se você quer algo benfeito, você tem que fazer sozinho" e esse modelo predominou na maior parte do século 20.

No final deste mesmo século, todavia, um certo número de fatores corroeu as bases da inovação fechada. Aumentou-se a mobilidade dos trabalhadores e esse fato tornou cada vez mais difícil para as empresas controlar suas próprias ideias e conhecimentos.

Nesse contexto, a ideia de que a administração pública, isoladamente, enfrenta dificuldades em lidar com problemas complexos é reforçada. Segundo relatório de 2010 da Organisation for Economic Co-operation and Development (OECD, 2010), os cidadãos podem desempenhar um papel maior na realização compartilhada nas metas das políticas públicas. Consequentemente, a gestão pública pode incluir o conhecimento e a experiência de usuários e agentes externos no processo de inovação e criação de valor: os cidadãos podem agir como colaboradores em tarefas públicas (HILGERS; IHL, 2010).

Essas afirmações são corroboradas por Copatti (2010), que alega que o Estado atual não consegue sozinho atender de forma satisfatória às demandas da sociedade sem uma aderência político-cidadã, que deve ser construída em um meio eficiente de comunicação, numa esfera pública voltada ao consenso e entendimento social pela participação dos atores sociais.

A resposta para muitos problemas públicos pode não estar mais somente na capacidade do Estado de incorporar conhecimento aos processos. As respostas podem estar em uma mudança de referencial: o lugar da inovação foi modificado (e, por consequência, o lugar do conhecimento). As possibilidades de conhecimento, agora abertas, são diversas. Cada vez mais se vê possibilidades maiores de outros atores também incorporarem conhecimentos aos processos governamentais (BOLLIGER, 2014).

É nesse contexto que os governos de democracias liberais têm tradicionalmente visto os seus cidadãos como constituintes e, assim, buscando avaliar e consultar a opinião pública. Pesquisas de opinião, as audiências e consultas públicas estão largamente voltadas para a compreensão do equilíbrio da opinião pública sobre as políticas e decisões governamentais (DUTTON, 2011).

Nesse sentido, a participação dos cidadãos na avaliação e transformações dos serviços e políticas públicas passa a se dar em um novo terreno (BOLLIGER, 2014). Se antes as fontes de participação popular eram, na maioria das vezes, consultivas, como nos casos dos orçamentos participativos, o relacionamento com o governo agora tornou-se público e não mais individualizado entre determinado cidadão com um órgão público.

É nesse cenário que surge a proposta de inserção dos conhecimentos externos nos processos de inovação governamental. A efetivação da proposta de inovação aberta na gestão pública, todavia, só começou a se tornar visível em 2009, quando Estados Unidos, Reino Unido, Canadá e Nova Zelândia anunciaram iniciativas de abertura de suas informações públicas (FREITAS; DARCOSO, 2014).

Uma das primeiras ações nesse sentido surgiu no governo Obama (20/1/200920/1/2017), nos Estados Unidos, com a criação do site data.gov. Essa plataforma aberta permite que qualquer pessoa com uma ideia possa criar serviços inovadores que conec- 
tem o governo aos cidadãos. No Brasil, as primeiras ações direcionadas às práticas de inovação aberta vieram em 2011 com a adesão do governo brasileiro a Open Government Partnership - OGP (CORDEIRO et al., 2012).

A OGP é uma iniciativa internacional que foi criada com a finalidade de assegurar compromissos concretos por parte dos governos de diversos países para promover a transparência, aumentar a participação cívica, combater a corrupção e aproveitar novas tecnologias para tornar o governo mais aberto, eficaz e responsável. Por meio da OGP os países-membros relacionam-se com os pares, empresas e outras organizações que possam ajudar a desenvolver soluções inovadoras para os problemas públicos. Para aderir à iniciativa cada país deve endossar uma declaração de princípios gerais e apresentar um plano de ação com compromissos assumidos, no sentido de promover um governo mais aberto, entretanto cada país assume compromissos de acordo com sua realidade (FREITAS; DARCOSO, 2014).

Tais processos colaborativos devem entender e envolver a sociedade não apenas como usuária e que faz escolhas, mas como criadora e formadora de políticas (TORRES, 2007). Conforme afirmam Lukensmeyer, Goldman e Stern (2011), de longe, o conjunto mais comum de abordagens para envolver o público no processo de inovação aberta governamental é o uso de ferramentas on-line. Essas plataformas sociais têm conquistado espaços nas organizações. São muitas as empresas que recorrem a essas plataformas para aumentar a sua produtividade, ampliar a interação entre departamentos e com clientes e potencializar a retenção e o fluxo de conhecimento. Assim como nas organizações privadas, muitos governos estão usando ferramentas de mídia social para informar o público sobre seus programas, construir relacionamentos com os cidadãos e solicitar sugestões sobre programas ou atividades governamentais.

De modo geral, a participação do público on-line está sendo usada para gerar novas ideias ou abordagens para resolver problemas, ampliar fontes de conhecimento, proporcionar maior acesso dos cidadãos aos agentes governamentais, educar o público, incentivar a colaboração e tornar mais fácil fornecer feedback formal ou informal sobre os planos, políticas ou programas.

Cabe destacar que, conforme aduz Bolliger (2014), essa ampliação das fontes de conhecimento não retira do gestor a capacidade de iniciativa ou de seu poder inovador. Pelo contrário, o multiplica, visto que ele tem a possibilidade de incorporação dos conhecimentos não governamentais. Constata-se que as organizações públicas têm a possibilidade de contar com uma rede cada vez mais aberta de relacionamentos, de elaboração e de deliberação conjunta acerca do que possa ser do interesse público.

Apesar de as ferramentas virtuais serem vistas como as principais formas de interação entre o governo e a sociedade, Lukensmeyer, Goldman e Stern (2011) identificaram três grandes grupos de formas de colaboração cidadã. O quadro a seguir mostra as formas disseminadas de participação e colaboração cidadã nos governos e seus tipos relacionados. 
Quadro 1 - Tipos de colaboração cidadã

\begin{tabular}{|c|c|}
\hline \multicolumn{2}{|r|}{ PARTICIPAÇÃO PÚBLICA ON-LINE } \\
\hline $\begin{array}{l}\text { Crowdsourcing ou } \\
\text { ideação }\end{array}$ & $\begin{array}{l}\text { Um processo aberto em que os cidadãos são convidados a partilhar e } \\
\text { votar em ideias que abordam um problema ou questão específica. }\end{array}$ \\
\hline $\begin{array}{c}\text { Concursos on-line ou } \\
\text { Competições }\end{array}$ & $\begin{array}{l}\text { Concursos ou desafios on-line que oferecem recompensas para aqueles } \\
\text { que desenvolvem soluções inovadoras para problemas específicos ou } \\
\text { desafios }\end{array}$ \\
\hline Wikis & $\begin{array}{l}\text { Sites que permitem aos visitantes editar páginas web existentes, } \\
\text { postar links e documentos e criar novas páginas interligadas. Mais } \\
\text { frequentemente são utilizados para agregar informações. }\end{array}$ \\
\hline $\begin{array}{l}\text { Câmaras Municipais } \\
\text { On-line }\end{array}$ & $\begin{array}{l}\text { Eventos em que o público faz perguntas ou comentários ao líderes } \\
\text { governamentais e tomadores de decisão que respondem em tempo } \\
\text { real }\end{array}$ \\
\hline Mídias sociais & $\begin{array}{l}\text { Blogs, Twitter, Facebook, Youtube e outras plataformas baseadas na } \\
\text { web nas quais os cidadãos possam interagir com os órgãos. }\end{array}$ \\
\hline \multicolumn{2}{|r|}{ PARTICIPAÇÃO PÚBLICA PRESENCIAL } \\
\hline $\begin{array}{l}\text { Sessões de escuta e } \\
\text { Audiências Públicas }\end{array}$ & $\begin{array}{l}\text { Sessões que permitem aos agentes governamentais ouvir o depoimento } \\
\text { e as declarações e responder às perguntas dos cidadãos e das partes } \\
\text { interessadas. }\end{array}$ \\
\hline $\begin{array}{l}\text { Fóruns de } \\
\text { stakeholders }\end{array}$ & $\begin{array}{l}\text { Sessões que reúnem partes interessadas e especialistas com } \\
\text { conhecimentos importantes para discutir e propor soluções para os } \\
\text { problemas públicos. }\end{array}$ \\
\hline Fóruns do Cidadão & $\begin{array}{l}\text { Sessões que permitem a diversos grupos de moradores e cidadãos } \\
\text { apresentarem problemas e criarem grupos para soluções de problemas. }\end{array}$ \\
\hline \multicolumn{2}{|r|}{ PARTICIPAÇÃO PÚBLICA FORMAL } \\
\hline $\begin{array}{l}\text { Consultivo Federal } \\
\text { Comitês }\end{array}$ & $\begin{array}{l}\text { Formalmente criados, fornecem ao governo informações com } \\
\text { conselhos e feedback do público. Compostos de partes interessadas e } \\
\text { especialistas. }\end{array}$ \\
\hline Regulamentação & $\begin{array}{l}\text { Procedimento que define como regulamentar as ações públicas e como } \\
\text { normatizar as regras federais e ainda definir qual o papel que o público } \\
\text { deve desempenhar na regulamentação do processo. }\end{array}$ \\
\hline $\begin{array}{l}\text { Fóruns do Residente } \\
\text { e do Cidadão }\end{array}$ & $\begin{array}{l}\text { Sessões que permitem diversos grupos da sociedade sejam engajados } \\
\text { nos processos decisórios governamentais. }\end{array}$ \\
\hline
\end{tabular}

Fonte: Adaptado de LUKENSMEYER; GOLDMAN; STERN (2011).

Por meio dessas ferramentas as contribuições individuais podem oferecer um grande valor coletivo. Os encontros presenciais, bem como as tecnologias como os wikis, blogs, redes sociais e aplicativos de compartilhamento de mídia liberam a criatividade das massas e podem facilitar a disseminação de ideias e experiências em um instante (DONEY, 2009).

O fato é que, na administração pública, essas possibilidades de ação ficam absolutamente subaproveitadas. Torres (2004) afirma que, em muitos casos, uma mesma e única estrutura administrativa poderia atender às demandas de determinado programa ou atividade necessários em alguns municípios ou Estados, porém nenhum esforço mais deliberado é feito no sentido de se aproveitar essas potencialidades.

Uma questão-chave para o sucesso da abertura do processo de inovação é a gestão do conhecimento. Conforme analisa Agune (2014), essas mudanças com tal sofisticação da agenda governamental vão exigir dos servidores públicos modelos mentais e 
competências totalmente diferentes das aplicadas anteriormente com o modelo fechado de inovação, o que inclui uma desconstrução de ambientes que são segregados e impedem a criação e o giro de ideias.

Desta maneira, o processo de inovação governamental nutre-se de uma cooperação entre os colaboradores internos e externos. O agente público, por sua vez, é chamado a criar e a atuar nesse contexto, não só como mero condutor da colaboração cidadã, mas como participante ativo do processo de construção coletiva das melhores soluções.

Nota-se que esse novo cenário recomenda um novo fôlego aos processos organizacionais dos governos, com vistas a priorizar a criação e o compartilhamento do conhecimento e o estabelecimento de um ambiente favorável à inovação continuada (CARLOS, 2014).

Jong, Kalvet e Vanhaverbeke (2010), todavia, alertam que a gestão da inovação aberta na gestão pública é bastante exigente. Para esses autores, os decisores políticos devem ter cuidado na criação e efetivação de iniciativas que podem ter um impacto sobre os gestores. Dessa forma, os gestores públicos devem em mente que medidas ma-projetadas ou a instituição malfeita destas medidas podem prejudicar práticas de inovação aberta, em vez de fomentá-las, afetando fortemente a credibilidade e a confiabilidade das propostas, como alerta Janssen et al. (2018).

Estudando as barreiras à adoção desse tipo de experiência, Gil-Garcia, Dawes e Pardo (2018) descrevem estudos que focalizam a compreensão de como redes abertas de plataformas de inovação como o Challenge.gov são usadas para postar problemas relacionados ao setor público e, em seguida, coletar e avaliar ideias apresentadas pelos cidadãos com o objetivo de inovação crescente do governo. Eles alertam para a descoberta e análise de fatores intra, inter e extraorganizacionais que impulsionam ou dificultam a introdução da inovação aberta no setor público.

Nessa perspectiva, Porumbescu, Neshkova e Huntoon (2018) argumentam que a transparência política das propostas e a compreensão das intenções das iniciativas podem ter efeitos na maior ou menor participação voluntária do público. Segundo Battaglio e Hall (2018), a desigualdade e as disparidades da participação no processo de inovação aberta na gestão pública serão inevitáveis, a menos que os gestores públicos estejam atentos a essas preocupações quando estiverem planejando oportunidades de participação.

Além disso, Battaglio e Hall (2018) admitem que pesquisas anteriores consideraram o desenho das propostas de participação como um elemento importante para solucionar problemas no nível de participação do público. Entender o que está por trás das escolhas das propostas, concentrando-se primeiro na compreensão do estabelecimento de problemas e, especialmente, na forma como são expressos, na sua narrativa, é fundamental para resolver problemas relacionados à participação do público.

\section{PERCURSO METODOLÓGICO}

Nesta pesquisa, e devido principalmente à sua natureza aplicada, trabalhou-se com geração de dados e procedimentos de análise dentro da abordagem qualitativa. Creswell (2010) indica que a pesquisa qualitativa deve ser utilizada quando inexiste um sólido corpo teórico sobre o fenômeno investigado e quando variáveis contextuais são consideradas importantes no problema. 
Devido à característica do trabalho, optou-se pela estratégia do estudo de caso, que é uma estratégia de pesquisa que se concentra na compreensão das dinâmicas em um contexto (EISENHARDT, 1989). Foi investigado o fenômeno contemporâneo da inovação aberta no governo de Minas Gerais dentro do seu contexto, visto que os limites entre o fenômeno e o contexto não estavam claramente definidos.

O estudo foi desenvolvido com um caso único, visto que o projeto Movimento Minas é considerado revelador para a temática abordada devido à característica de ser uma política pioneira na administração pública brasileira, em seus diversos níveis, que é baseada nas premissas da inovação aberta. Na coleta de dados foram realizadas entrevistas semiestruturadas, pesquisa documental e observação direta. A pesquisa documental foi feita em meios digitais e presencialmente na sede do Escritório de Prioridades Estratégicas na Cidade Administrativa Tancredo Neves (sede do governo de Minas Gerais).

Em relação às entrevistas, foram ouvidas nove pessoas, durante $11 \mathrm{~h} 30 \mathrm{~m}$, entre 2013 e 2014. Oito delas foram ouvidas presencialmente, e em diversos momentos. Além de sondagens individuais com os entrevistados, ocorreram algumas reuniões ampliadas para escuta e relato das experiências dos seguintes entrevistados:

Quadro 2 - Atores pesquisados

\begin{tabular}{|c|c|c|}
\hline Entrevistado & Cargo & Função no Projeto \\
\hline E1 & $\begin{array}{c}\text { Coordenadora do Núcleo de } \\
\text { Sistemas e Gestão (Livre nomeação) }\end{array}$ & Gerente do Movimento Minas \\
\hline E2 & Empreendedora Pública & Gestora de Conteúdo/Comunicação \\
\hline E3 & Empreendedora Pública & Gerenciamento de projetos \\
\hline E4 & Empreendedor Público & Gerenciamento de projetos \\
\hline E5 & Empreendedor Público & Gerenciamento de projetos \\
\hline E6 & $\begin{array}{c}\text { Chefe de Comunicação (Livre } \\
\text { nomeação) }\end{array}$ & Cogestor - Comunicação \\
\hline E7 & Empreendedor Público & Gerente do Movimento Minas \\
\hline E8 & $\begin{array}{c}\text { Especialista em Políticas Públicas e } \\
\text { Gestão Governamental }\end{array}$ & Analista de cocriação \\
\hline E9 & $\begin{array}{c}\text { Especialista em Políticas Públicas e } \\
\text { Gestão Governamental }\end{array}$ & Apoio \\
\hline
\end{tabular}

Fonte: Elaborado pelos autores (2014).

A observação participante foi realizada de duas formas distintas: participação nas discussões na plataforma virtual do projeto e vivência no ambiente de trabalho e gestão do Movimento Minas.

A análise dos dados da pesquisa foi desenvolvida por meio da técnica hermenêutico-dialética, a qual, segundo Minayo (2008), é um caminho de possibilidades de construção teórico-metodológica de base empírica e documental para as pesquisas qualitativas, que não se limita à exposição do como fazer, mas que abarca também o como pensar.

\section{TRAJETÓRIA E EXPERIÊNCIAS DE INOVAÇÃO ABERTA NO PROJETO}

O projeto Movimento Minas foi criado pela publicação da Lei Delegada 181, de 20 de janeiro de 2011, que também criou o Escritório de Prioridades Estratégicas do Governo do Estado de Minas Gerais, órgão autônomo, com status de Secretaria de Esta- 
do, ligado diretamente ao governador (período 2011-2014) e que coordenava o projeto em parceria com as Secretarias e demais órgãos estaduais. O Escritório de Prioridades Estratégicas já existia na gestão estadual de 2007-2010, mas era um departamento da Secretaria de Planejamento, responsável por indicadores, saneamento de contas, contratos de gestão do governo.

O projeto foi proposto por um grupo de técnicos que já integravam o governo estadual anterior (lembrando que as duas gestões estaduais no período de 2007 a 2014 eram do mesmo partido político), respaldados e apoiados pela então diretoria do Escritório de Prioridades Estratégicas, sendo imediatamente aceito pelo governador e pelo Núcleo Estratégico do Governo. A equipe do projeto foi formada tanto por servidores de carreira quanto por empreendedores públicos (profissionais recrutados e selecionados especificamente para atuarem em um dos núcleos do Escritório de Prioridades Estratégicas).

Tratando-se de um trabalho inédito nas atividades do setor público do Estado de Minas Gerais, o processo de criação e desenvolvimento do projeto passou por diversos estágios, muitas vezes com indefinições de papéis, estruturações mais ou menos centralizadas e/ou descentralizadas, redefinições de escopo.

O Movimento Minas foi operacionalizado de maneiras diversas, porém com referências importantes, como o OpenIDEO, Challenge.gov e Innocentive, no que diz respeito à construção e manutenção do site, e alguns projetos inspiradores: o Mindlab (Dinamarca) e Nesta (britânico), no que diz respeito aos processos.

O projeto foi sendo estruturado em fases não muito bem definidas. Uma delas consistiu em testar um processo desenhado com base numa mescla entre Design thinking (metodologia de inovação inspirada no trabalho de designers) e open innovation. Após essa fase foram pensados processos de participação mais curtos e com incentivos mais claros aos participantes (prêmios). E a última modificação na estrutura aconteceu depois das manifestações de junho de 2013, ocorridas em diversas cidades do Brasil, o que desencadeou a necessidade de repensar o direcionamento do projeto e retomar o caminho de um laboratório de diálogo político, como será apresentado na seção seguinte, baseada na trajetória e experiências do projeto.

\section{Primeira Fase}

A primeira fase do projeto coincide com a nova formação do Escritório de Prioridades Estratégicas e a transição na gestão do governo estadual (gestão 2007-2010 para gestão 2011-2014).

Logo no início do projeto os procedimentos podiam ser assim descritos: inicialmente, por meio do site do Movimento Minas, a equipe convidava os participantes a propor ideias para promover melhorias para Minas Gerais. Qualquer pessoa poderia participar, quer sugerindo ideias, apoiando ou comentando as ideias dos outros participantes.

Nessa primeira fase era possível inserir links de artigos e vídeos para contextualizar a ideia sugerida e mostrar exemplos de outros Estados e países. Dentro da proposta estavam previstos também eventos off-line, denominados de "encontros inspiradores", com palestras sobre os temas dos desafios e avaliação de especialistas e cidadãos sobre como viabilizar as ideias apresentadas. 
Nesse formato inicial as propostas, após serem discutidas na plataforma virtual, eram compiladas durante um evento, para serem transformadas em propostas de soluções reais. A partir desse ponto viria a análise de viabilidade, com testes em pequena escala, para se mensurar efetividade de resultados que permitiriam ampliar a política ou programa, reformular ou ainda encerrar a ação por falta de efetividade.

Todas as áreas de atuação do governo do Estado de Minas Gerais poderiam ter projetos, que iriam desde as ideias para a redução da pobreza, passando por empregabilidade e crescimento profissional, moradia, inovação, segurança, cultura e sustentabilidade ambiental.

\section{Segunda Fase}

Num segundo momento, após a análise dos resultados da primeira fase, a forma de interação foi modificada. Para a equipe, havia um desafio a ser vencido: o cidadão vinha ao ambiente virtual criado pelo governo e trazia a sua colaboração para a definição de políticas e programas, mas havia uma pergunta que ainda soava alto para os integrantes do projeto: Como viabilizar a análise e efetivação de tanta informação?

Constatou-se que a tematização muito aberta, à medida que permitia um turbiIhão de novas ideias, não possibilitava, pelo volume, sua devida análise e ação. Retomou-se, assim, a ideia de lançar temas específicos para a participação das comunidades, num fluxo de três fases: desafio, ideias e ação. Os temas eram escolhidos com base em prioridades do governo e no contato preexistente com participantes da sociedade. Um exemplo desse processo é descrito por E4:

A gente escolheu o tema de gravidez na adolescência, em função de conversas com a secretaria de saúde. Aí, a gente foi na sociedade ouvir quais eram os principais problemas relacionados a esse tema. Desses problemas nós escolhemos um e voltamos para a sociedade buscar ideias para resolver esse problema.

Conforme afirmam Kadouaki e Marra (2013), fora do mundo virtual, mas em sintonia com ele, funcionava a plataforma presencial do Movimento Minas, composta por encontros para trazer as pessoas com as ideias mais destacadas no site, além de lideranças do setor privado, de organizações sociais, das universidades e do governo, para discutir desafios, gerar ideias inovadoras e desenhar formas de colocá-las em prática, seja pelo governo ou pela sociedade. Foi verificada a utilização do modelo composto por três fases: escuta, ideias e ações (Quadro 3).

Quadro 3 - Fluxo do processo de inovação aberta na segunda fase do Movimento Minas

\begin{tabular}{|c|l|}
\hline FASE & \multicolumn{1}{|c|}{ DETALHAMENTO } \\
\hline Escuta & $\begin{array}{l}\text { - As pessoas são incentivadas a conversar virtual e presencialmente sobre temas } \\
\text { relevantes, escolhidos pela equipe do projeto, sempre relacionados a desafios da } \\
\text { sociedade mineira. } \\
\text { - As conversas acontecem no site do projeto, em encontros de escuta, reuniões ou } \\
\text { outros momentos. }\end{array}$ \\
\hline
\end{tabular}




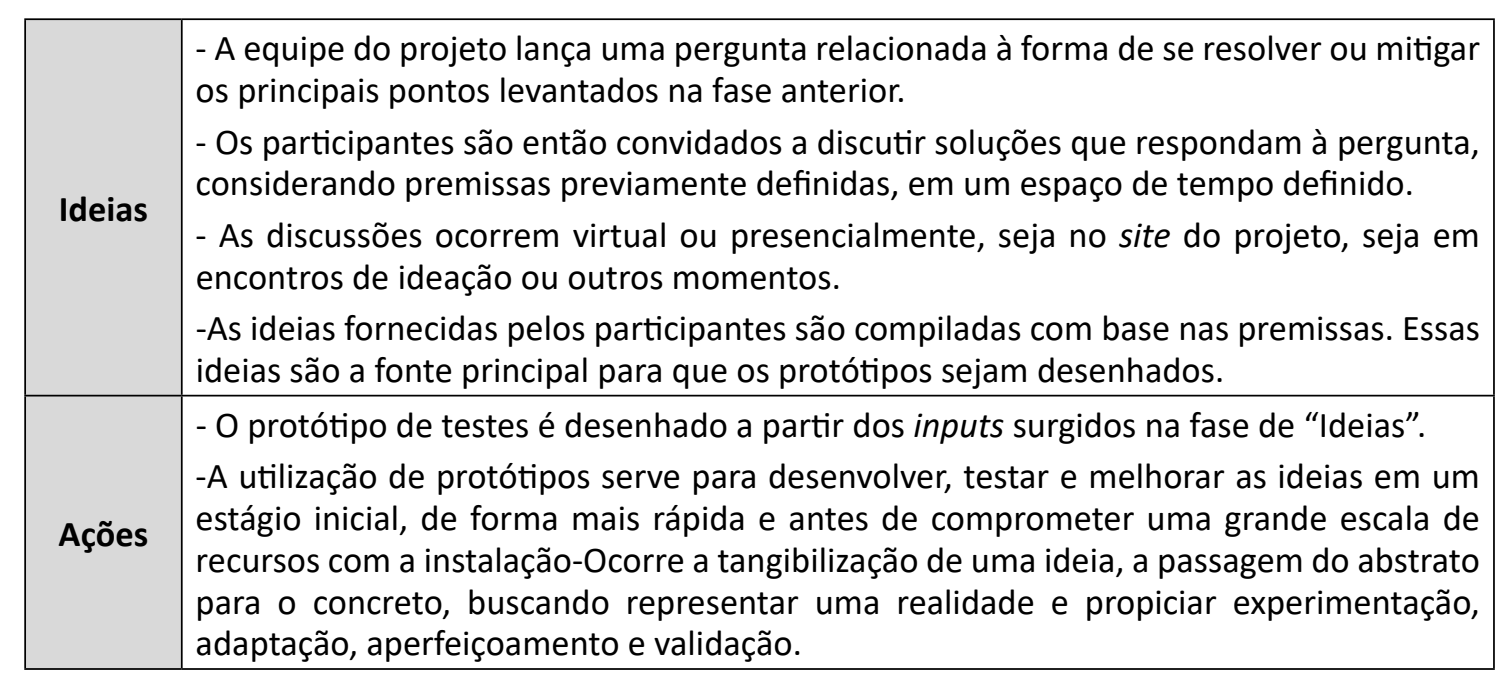

Fonte: Adaptado de KADOUAKI; MARRA (2013).

Para cada fase do modelo utilizado existia um fluxo específico. Projetou-se que o cidadão seria atraído, conheceria o conteúdo e faria a sua colaboração. Essa colaboração seria compilada juntamente com as demais e os gerentes de projetos fariam os relatórios relativos à ação.

Ainda sobre o uso das informações, quando o usuário publicava conteúdo na plataforma do Movimento Minas, isso significava que este usuário estaria permitindo que todos os demais, incluindo pessoas fora do Movimento Minas, pudessem acessar e utilizar essas informações e associá-las ao usuário, todavia um problema parecido com o ocorrido na primeira proposta continuava a acontecer, conforme relatam:

Mas foi nessa etapa, na prática, que a gente descobriu que demorava mais tempo, a gente perdia um pouco o timing. Por exemplo, o governo tem 4 anos, a gente estava rodando um projeto em 9 meses, não poderia ser assim (E6).

Uma possível explicação para esses problemas iniciais pode ter sido a forma de como a política foi estabelecida. Conforme preveem Hilgers e Ihl (2010), Lukensmeyer, Goldman e Stern (2011), a efetivação da inovação aberta precisa passar por fases iniciais para que possa obter maior sucesso. Primeiramente, conforme afirmam tais autores, propõe-se um processo de transparência estatal em que os dados governamentais são abertos a todos os cidadãos interessados. Posteriormente abre-se um processo de diálogo com esses cidadãos, quando se iniciam as primeiras práticas de participação. Nessa etapa acentua-se um processo de educação dos cidadãos e dos agentes públicos sobre o novo modelo a ser adotado. Por fim, com as duas primeiras etapas já consolidadas, abre-se para o processo colaborativo, a inovação aberta em si. Os próprios membros do Movimento Minas reconhecem que "na efetivação do projeto essas duas fases iniciais não foram muito bem trabalhadas", conforme afirma E4.

\section{Terceira Fase}

As manifestações sociais que eclodiram no Brasil em 2013 mobilizaram os gestores do programa a ir às ruas conversar e, principalmente, escutar o que se denominou "a voz das ruas". 
Após o período das manifestações a plataforma do Movimento passou a ser utilizada de outra maneira. Dessa vez a gestão do Movimento decidiu que a participação e colaboração da sociedade ocorreriam da maneira mais livre possível.

Apesar de ter modificado a forma de interação com a sociedade, o Movimento Minas não mudou a arquitetura do site. Apenas foram feitas algumas adaptações para melhor contextualizar o momento. Uma das principais modificações foi nos conceitos apresentados no site. Os gestores admitiram que, por exemplo, a palavra "desafio" era mal- interpretada pelas pessoas. Trocaram-na pela palavra "destaque".

\section{Quarta Fase}

Após as mobilizações de 2013, a equipe do projeto decidiu não mais apenas aguardar a participação do cidadão no site oficial, mas também buscar o cidadão que dseja interagir e contribuir, por meio de busca ativa (por parte da equipe) em todos os canais de comunicação disponíveis no ambiente virtual.

Outra alteração também advinda das manifestações populares de 2013 foi o retorno da amplitude de temáticas tratadas pelo projeto. Enquanto na segunda etapa os temas eram restritos aos dez desafios do governo previstos em seu planejamento estratégico, nessa fase a gestão do projeto optou por colocar as temáticas com base no que foi discutido nas manifestações.

Apesar dessa proposta de trabalhar de forma mais aberta aspirações da sociedade, verificou-se, na fala de alguns entrevistados, que a decisão pelas temáticas a serem discutidas ainda era, na sua totalidade, tomada pelo governo.

Nessa fase, o Movimento Minas começou a atuar com uma estrutura baseada em Gestão de Projetos. Segundo E1, o fluxo das informações surgia a partir de uma ideia, em uma fase de iniciação,

que pode ser conduzida por qualquer pessoa, não necessariamente o gerente de projetos. Essa pessoa descreve o que é aquela ideia, é feita a análise de viabilidade e depois é feita uma validação. Se não for possível é arquivado e se for possível já entra dentro da lógica de projetos mesmo.

Nessa fase a própria equipe reconhecia que houve um retrocesso no que diz respeito às ideias e conceitos da inovação aberta e do design thinking. Além disso, foi necessário se adequar a um novo cenário de governo, em que se exigiam projetos que envolvessem parcerias. Nesse novo contexto as ações seriam desenvolvidas com a participação de diversos atores (internos ou externos), mesmo possuindo um gerente interno da equipe. O processo de incubação da ideia foi redefinido e houve uma percepção maior das distinções entre a função de gerente de projetos e do gerente de produto. Para E1, os cidadãos poderiam atuar como gerentes de produto:

Uma pessoa deu uma ideia, então ela está imaginando uma iniciativa, um evento, uma intervenção. Ela tem a possibilidade de ser a gerente daquele produto. Ou seja, uma pessoa que vai acompanhar durante todo aquele tempo.

Segundo E1, porém, não haveria como o cidadão ser gerente de projeto, porque ele não participa do fluxo interno da administração e, por outro lado, para ser gerente de projeto é necessário ter competência e perfil para a função. O mesmo entrevistado 
ressaltou ainda que a necessidade do governo em exercer controle sobre as atividades envolvidas em algum projeto inviabilizaria a delegação de gestão de projetos para o cidadão.

Nessa fase, o fluxo era iniciado quando alguma pessoa ou grupo de pessoas (interno ou externo ao governo) gerava uma ideia. A partir desse ponto planejava-se uma iniciativa, um evento, uma intervenção. Na visão do projeto, essa pessoa seria um Gerente do Produto (quem sugeriu o projeto).

Além dessas ações havia também um fluxo inverso, em que os gestores dos diversos órgãos e secretarias iam buscar no Movimento Minas informações e ideias advindas da sociedade, conforme conta um dos atores:

Tem algumas políticas públicas que as secretarias estão para tomar decisão e tem que ouvir o cidadão. Então a gente ajuda nisso (E5).

Nessa fase, a equipe do Movimento Minas também fazia uma importante reflexão interna: O projeto mantém a ideia de inovação aberta, em sua essência, conforme as bases teóricas? Alguns entrevistados admitiam que não sabiam mais se o projeto mantinha-se dentro dessa perspectiva, haja vista que ele se modificou muito para se ajustar às necessidades governamentais e sociais que foram se modificando ao longo dos quatro anos de sua existência.

\section{OS PRINCIPAIS OBSTÁCULOS NA TRAJETÓRIA DO PROJETO}

Apesar do apoio integral do governador, a equipe do projeto relatou que a necessidade de "vender" internamente a proposta para os secretários de cada pasta "custou bastante energia" dos membros do Movimento Minas.

Essas questões que parecem colocar em lados opostos o Movimento Minas e as Secretarias não são incomuns na administração pública, conforme já analisado por Denhardt (2012) e no depoimento de E3:

O Estado tem alguns canais que são os canais clássicos: as ouvidorias, os conselhos, que são canais institucionalizados. Quando a gente fala de inovação aberta, de design thinking, isso causa um estranhamento por ser uma forma diferente (E3).

Por outro lado, o projeto já passou por diversos formatos e também descontinuidades. Algumas foram impactantes, posto que modificaram até a forma de funcionamento do projeto. O respondente E7 conta que "houve mudanças de gerência e da diretoria do Escritório. Todas tiveram impacto nas diretrizes e na forma de funcionamento".

Outro importante desafio era relacionado a própria identidade e função do projeto: inclusive para os membros da equipe não era fácil explicá-lo. Aliada a essa questão, um enorme desafio era atrair a participação das pessoas. Como analisa a respondente E6, era negativamente expressivo o desinteresse da sociedade na medida em que o projeto era visto como uma ação governamental, e, assim, distante da realidade dos cidadãos.

De fato, o dilema era como promover o engajamento social sem transformar o projeto em um marketing governamental: "uma das coisas que eu falo é isso: gente, o movimento não é publicidade" (E6). Nesse aspecto os membros da equipe não conseguiam visualizar uma solução. 
Nessa perspectiva, o desenho das propostas e oportunidades participativas, elemento muito enfatizado por Battaglio e Hall (2018) parece ser uma questão fundamental para definição da identidade e função do projeto, algo que não foi devidamente entendido e conduzido internamente. As dificuldades de compreensão do projeto pela equipe e o desenho de propostas de participação e estabelecimento dos desafios são marcas bastante fortes na trajetória de vida do projeto.

Em termos da adesão ao projeto, a mudança de percepção do cidadão em relação a sua própria participação no governo constituía-se em desafio. Para a respondente E6, "é muito difícil por que o cara quer falar que o trânsito é uma porcaria, mas esse mesmo cara não quer sentar e debater possíveis soluções". E isso ocorre porque, na interpretação da respondente E6, se o cidadão "senta" e debate os problemas, ele passa a ser corresponsável pelo processo e não pode reclamar mais.

Para os gestores do projeto, esse era o grande desafio: sensibilizar nos cidadãos a cultura da participação, a cultura da colaboração, a cultura da cocriação, mas não foi identificada nenhuma ação mais estruturada do projeto nesse sentido. Desse modo, pode-se admitir que a oportunidade de uma compreensão mais profunda da interação governo/cidadãos foi perdida, bem como o entendimento dos fatores que direta ou indiretamente influenciam a maior ou menor confiabilidade nesse tipo de proposta por parte do público, aspectos fortemente recomendados por Janssen et al. (2018) na gestão de experiências como o Movimento Minas.

Foi constatado que, apesar do apoio formal do governador às ações do projeto, existiam reações internas ao governo contrárias ao Movimento Minas. A falta de definição do papel do projeto internamente constituiu-se em uma das grandes fragilidades do projeto. Possivelmente o que ocorreu foi uma falta de clareza interna entre o nível estratégico e as Secretarias desde a concepção do projeto. Na fala dos entrevistados percebe-se que há um grande desgaste quando o assunto é a concretização das políticas. Observa-se que além do trabalho para "vender" o projeto externamente para a sociedade, havia um desgaste interno para sua disseminação e legitimação.

Ou seja, você chega no lugar e diz: vou fazer um projeto para você melhorar a sua atuação, você vai fazer comigo? Vou. A única coisa que eu preciso é o seguinte: no fim você tem que rodar essa solução. E aí no meio o processo quebra. Ou chega no fim e recebemos: não, isso aqui a gente não pode. Mas a gente combinou, não foi? (E6).

Outro ponto importante nessa perspectiva analisada por E6 relaciona-se ao processo decisório. Conforme destaca, apesar da existência de discussões colaborativas o processo decisório era centralizado no governo: “E aí? Depois você vai comprar a ideia? O governador compra. E quem opera? Não temos essa garantia. Esse também é um desafio" (E6).

Revendo o argumento de Porumbescu, Neshkova e Huntoon (2018) a respeito da necessidade de transparência política das propostas e a compreensão (interna) das intenções das iniciativas por parte dos gestores públicos, esse tipo de situação experimentada no projeto reforça a necessidade de prioritária atenção a essas questões por ocasião do planejamento de projetos dessa natureza. Há ainda um agravante nesse 
ponto: além da não existência de convicção interna quanto aos objetivos do projeto e sua importância para o governo, existia uma força limitadora das Secretarias quanto à atuação do projeto.

Não tem fluxo definido. E nós somos dependentes de cada tipo de secretaria, cada tipo de gestor e cada tipo de assunto. Dependia até do humor do secretário (E4).

Os membros do Movimento reconheciam que não era simples lidar com essa situação. Ademais, que existiam outros processos de construção de políticas que já eram institucionalizados, criados por lei ou por iniciativas governamentais e que não deviam ser simplesmente abolidos, conforme é apresentado por E3: “A Secretaria de Saúde, por exemplo, se você for pegar as metas dela são quase todas obrigatórias por lei".

A dificuldade em lidar com os procedimentos internos era acentuada na medida em que o Movimento Minas trazia para dentro da estrutura governamental ferramentas e fluxos ainda inexistentes. Dessa forma, as limitações legais e burocráticas e estando o projeto inserido formalmente na estrutura estatal implicava diversos obstáculos, conforme comenta E6: "Por exemplo, quando você vai contratar recursos para fazer um Hackathon, como você justifica isso para o Tribunal de Contas?".

Os obstáculos indicados por E6 são identificados por Gil-Garcia, Dawes, Pardo (2018) quando argumentam que algumas barreiras intra, inter e extraorganizacionais podem dificultar ou impedir que organizações do setor público adotem essa inovação processual e tecnológica. Admite, no entanto, que quando o mandato político é alinhado com a missão da organização que propõe a inovação, oportunidades para mudanças e inovação em procedimentos operacionais padrão podem ser adotadas mais facilmente, mas depende muito da força política que os projetos adquirem.

Mais um desafio para o Movimento Minas estava relacionado à melhoria da qualidade da participação na Internet. Na visão dos membros da equipe, as pessoas participam muito melhor presencialmente. A equipe buscava soluções para aperfeiçoar as participações nas ferramentas virtuais tendo em vista as limitações financeiras para os encontros presenciais.

Há que se falar aqui em um processo importante: a institucionalização do projeto, pois conforme prevê Paes de Paula (2005), as arenas de participação e colaboração só serão efetivas se essas ações governamentais forem institucionalizadas, uma vez que isso daria espaço para a população participar efetivamente das suas políticas, entretanto os gestores do projeto tinham uma visão um pouco conservadora nesse sentido. Um fator determinante para isso é o próprio caráter da ação governamental. O Movimento Minas nasceu como projeto, ou seja, tinha prazo para ser finalizado. O projeto existiria formalmente até 31/3/2015, conforme previsto no Decreto Estadual no 45.578, de 28 de março de 2011.

Ainda sobre a institucionalização do projeto, um aspecto importante é a sua capacidade de obter legitimação, tanto internamente quanto externamente, o que parece ter sido um ponto vital, crítico e problemático na condução e finalização do Movimento Minas. Como afirmam Janssen et al. (2018), a legitimidade externa é baseada na confiança dos cidadãos e algumas dimensões são centrais para a confiabilidade: compe- 
tência, boas intenções, honestidade e consistência, e elas refletem mais a avaliação dos cidadãos a respeito dos funcionários ou técnicos responsáveis por desenvolver, manter e monitorar o sistema do que a sua avaliação.

Considerando a previsão da sua extinção, o que de fato ocorreu em março de 2015, E2 apontava que o registro formal das ações era uma das preocupações da equipe.

Os três passos apontados por Hilgers e Ihl (2010), Lukensmeyer, Goldman e Stern (2011), quais sejam, a construção de um novo modelo de gestão, desde o desenvolvimento e a instituição dos conceitos de transparência dos governos, a participação popular comprometida com o controle do orçamento e as políticas públicas desenvolvidas, chegando, por fim, ao trabalho da inovação aberta para a definição de políticas públicas com a participação direta do cidadão, podem não ter sido cumpridos e etapas terem sido atropeladas. Além da função essencial e o objetivo do projeto, outra perspectiva analisada diz respeito a sua sustentabilidade. Certamente, o Movimento Minas não foi um projeto de fácil planejamento, pelas questões internas, institucionais e, principalmente, políticas. A sustentabilidade do projeto nesse cenário era realmente muito difícil, especialmente considerando que o projeto nasceu em governo estadual com projeto político antagônico ao governo do período 2014/2018, incompatibilidade realçada fortemente nas eleições de 2014.

\section{CONSIDERAÇÕES FINAIS}

A partir da observação e análise da trajetória do Movimento Minas, percebeu-se uma forte indefinição na própria prática da inovação aberta. Não é possível afirmar que o projeto em seus diversos momentos referia-se a um processo de cocriação, design thinking e colaboração coletiva. Em outras palavras, não se pode afirmar que as ideias dos cidadãos foram realmente captadas pelo ente governamental. O que houve foi uma tentativa (que os membros da equipe preferem chamar de laboratório) de estreitar os laços entre governo e sociedade.

O tom do discurso dos gestores do projeto evidenciava a sua preocupação em ressaltar que não era objetivo do projeto captar ideias dos cidadãos para construção de políticas públicas, mas envolvê-lo e engajá-lo , visando ao estreitamento da ligação entre o governo e a sociedade. Sendo assim, pode-se afirmar que o Movimento Minas foi um projeto de inovação aberta?

O processo foi concebido de maneira abrupta, sem a devida preparação do governo e dos cidadãos. Além disso, parece que não havia uma definição clara do conceito de inovação aberta no governo com o objetivo de apropriação do conhecimento social para utilização no processo de inovação pública. E, segundo apresentado por Bolliger (2014), o governo reconhece uma exigência social de (re)inventar formatos de relacionamento entre o Estado e a sociedade por meio de espaços de confiança entre governantes e governados. 
Conforme foi constatado durante as mobilizações de 2013, um diálogo direto, claro e efetivo entre governo e sociedade é quase inexistente, com falhas de ambos os lados. Por outro lado, janelas de oportunidade de construção de novos ambientes de participação pública proporcionados pelas TICs são evidentes, mas nota-se grande dificuldade em introduzir o cidadão no processo de construção da política.

Esses novos projetos, mesmo que ainda em fase embrionária dentro das estruturas estatais, apontam para uma consonância com os desejos da sociedade que sinaliza por diversas fontes um desejo de cada vez mais adicionar formas de participação direta à democracia representativa. Afinal, conforme afirma Lessig (2009), as virtudes e utilidade de projetos que propõem a transparência, participação e colaboração, são óbvias. Abrir o processo de participação direta, todavia, exige uma mudança cultural abrupta dos órgãos que estão, na sua maioria, acostumados a tomarem suas decisões sozinhos.

Por outro lado, como afirmam Gil-Garcia, Dawes e Pardo (2018), é difícil imaginar na atualidade alguma atividade ou função governamental que não envolva intensamente o uso de informações e tecnologia. O uso das TICs no governo, segundo os autores, amplia as perspectivas de uma gestão mais eficiente, transparente e eficaz, ao mesmo tempo que requer alterações nos modelos tradicionais da gestão púbica, bem como novos estilos de liderança, processos decisórios, novos padrões de responsabilidade e engajamento social (GIL-GARCIA; DAWES; PARDO, 2018).

Reitera-se, portanto, que o objetivo deste estudo, mais do que apresentar soluções e/ou conclusões, foi de fomentar novos processos de discussão a respeito da temática da inovação aberta na gestão pública. A expectativa também é de que, além de estimular novos processos de discussão, estudos sobre a temática eleita contribuam para a construção de conhecimento e orientação prática para processos similares no âmbito governamental. Aponta-se, a partir da presente pesquisa, para a necessidade de investimento em estudos que investiguem as nuances da inovação aberta no governo em outras esferas (federal e municipal) e/ou poderes (Legislativo e Judiciário), bem como o aprofundamento de questões levantadas por este estudo.

Finalmente, a análise comparativa de processos desse tipo em curso no mundo, além de pesquisas com abordagens sobre os fluxos e mecanismos adotados pelos órgãos públicos na operacionalização da inovação aberta, são também possibilidades de aprofundamento do conhecimento de um tema de grande importância e impacto e ainda muito pouco conhecido.

\section{REFERÊNCIAS}

ANDRADE, Jackeline A. de. O processo de inovação nas organizações públicas: integrando conceitos às práticas. In: ENCONTRO ANUAL DA ANPAD, 25., 2001, Campinas. Anais [...]. Campinas: Anpad, set. 2001. AGUNE, Roberto. O governo no século XXI. In: AGUNE, Roberto (ed.). Gestão do conhecimento e inovação no setor público. São Paulo: Secretaria de Planejamento e Desenvolvimento Regional, 2014. p. 57-92.

BATTAGLIO Paul; HALL, Jeremy. Time's Up: Equity, Fairness, and Public Administration. Public Administration Review, v. 78, n. 3, p. 335-337, 2018.

BOLLIGER, Sérgio. Inovação depois da nova gestão pública. In: AGUNE, Roberto (ed.). Gestão do conhecimento e inovação no setor público. São Paulo: Secretaria de Planejamento e Desenvolvimento Regional, 2014. p. 24-56. 
BRANDÃO, Soraya M.; BRUNO-FARIA, Maria de Fátima. Inovação no setor público: análise da produção científica em periódicos nacionais e internacionais da área de administração. Revista de Administração Pública, Rio de Janeiro, v. 47, n. 1, p. 227-248, jan./fev. 2013.

BRASIL. Lei no 12.527 de 18 de novembro de 2011. Diário Oficial da União, 18 nov. 2011. (Ed. extra).

CARLOS, José A. Inovação organizacional no setor público. In: AGUNE, Roberto (ed.). Gestão do conhecimento e inovação no setor público. São Paulo: Secretaria de Planejamento e Desenvolvimento Regional, p. 50-73, 2014.

CHESBROUGH, Henry W. The era of open innovation. MIT Sloan Management Review, v. 44, n. 3, p. 34-41, 2003.

CHIARONI, Davide; CHIESA, Vittorio; FRATTINI, Frederico. The open innovation journey: howfirms dynamically implement the emerging innovation management paradigm. Amsterdam: Technovation, 2009.

COHEN, Wesley; LEVINTHAL, Daniel. Absorptive capacity: a new perspective on learning and innovation. Administrative Science Quaterly, v. 35, n. 1, p. 128-152, mar. 1990.

COPATTI, Livia. C. A efetivação da cidadania através da participação no poder local. Perspectiva, v. 34 , n. 126, p. 85-100, jun. 2010.

CORDEIRO, Antonio; MARTINS, Claudia; SANTOS, Nilton; RIBEIRO, Rodrigo; PETRA, Thiago. Governo eletrônico e redes sociais: informação, participação e interação. Revista Eletrônica de Comunicação, Informação e Inovação em Saúde, v. 6, n. 2, p. 1-8, jun. 2012.

CRESWELL, John W. Projeto de pesquisa: métodos qualitativo, quantitativo e misto. 3. ed. Porto Alegre: Artmed; Bookman, 2010.

CUNHA, Maria Alexandra; COELHO, Taiane Ritta; PRZEYBILOVICZ, Erico. Get into the club: positioning a developing country in the international e-gov research. The Electronic Journal of Information Systems in Developing Countries EJISDC, v. 79, n. 4, p. 1-21, 2017.

DAMANPOUR, Fariborz; WALKER, Richard; AVELLANEDA, Claudia. Combinative effects of innovation types and organizational performance: A longitudinal study of service organizations. Journal of Management Studies, v. 46, n. 4, p. 650-675, 2009.

DENHARDT, Robert. Teorias da administração pública. 6. ed. São Paulo: Cencage Learning, 2012.

DONEY, Dan. Structured crowdsourcing: harnessing external expertise in government. In: GOTZE, John; PEDERSEN, Christian (ed.). State of the eUnion: Government 2.0 and Onwards. Bloomington: AuthorHouse, 2009.

DUTTON, Willian. Networking distributed public expertise: strategies for citizen sourcing advice to government. One of a Series of Occasional Papers in Science and Technology Policy, Pennsylvania Avenue; Washington DC: Science and Technology Policy Institute; Institute for Defense Analyses, 2011.

EISENHARDT, Kathleen. Building theory from case study research. Academy of Management. Review, v. 14, n. 4, p. 532-550, out. 1989.

FREITAS, Rony Klay Viana de; DARCOSO, Antonio Luiz Rocha. Inovação aberta na gestão pública: análise do plano de ação brasileiro para a Open Government Partnership. Revista de Administração Pública. v. 48, n. 4, p. 869-888, 2014.

GIL-GARCIA, Ramon J.; DAWES, Sharon; PARDO, Theresa. Digital government and public management research: finding the crossroads. Public Management Review, v. 20, n. 5, p. 633-646, 2018.

HILGERS, Dennis; IHL, Jan. Citizensourcing: Applying the Concept of Open Innovation to the Public Sector. International Journal of Public Participation, v. 4, n. 1, p. 67-88, 2010.

HIPEL, Erick. The sources of innovation. Oxford: Oxford University Press, 1988.

JACOBI, Pedro; PINHO, José Antonio G. Inovação no campo da gestão pública local: novos desafios, novos patamares. São Paulo: FGV Editora, 2006.

JANSSEN, Martin; RANA, Nripendra; SLADE, Emma; DWIVEDI, Yogesh. Trustworthiness of digital government services: deriving a comprehensive theory through interpretive structural modelling. Public Management Review, v. 20, n. 5, p. 647-671, 2018.

JONG, Jeroen; KALVET, Tarmo; VANHAVERBEKE, Wim. Exploring a theoretical framework to structure the public policy implications of open innovation. Technology Analysis \& Strategic Management, v. 22, n. 8, p. 877-896, 2010.

JORDÃO, Claudia. A cidadania na reforma do Estado: redefinição de conceitos e consequências práticas. ENCONTRO NACIONAL DE ADMINISTRAÇÃO PÚBLICA E GOVERNANÇA, 5., 2012, Salvador. Anais [...]. Salvador, 2012.

KADOUAKI, Ricardo; MARRA, Cícero Nogueira. Inovação aberta e design thinking no setor público: o caso da "gravidez na adolescência" no movimento Minas. In: CONGRESSO CONSAD DE GESTÃO PÚBLICA, 6., 2013, Brasília. Anais [...]. Brasília, 2013. 
KLERING, Luis; ANDRADE, Jackeline A. Inovação na gestão pública: compreensão do conceito a partir da teoria e da prática. In: JACOBI, Pedro; PINHO, José. Antonio. G. (ed.). Inovação no campo da gestão pública local: novos desafios, novos patamares. Rio de Janeiro: FGV Editora, 2006. p. 77-97, 2006.

KOKKINAKOS, Panagiotis; KOUSSOURIS, Sotirios; PANOPOULOS, Dimitrios; ASKOUNIS, Dimitrios; RAMFOS, Antonis; GEORGOUSOPOULOS, Christos; WITTERN, Erik. Citizens Collaboration and Co-Creation in Public Service Delivery: The COCKPIT Project. International Journal of Electronic Government Research (IJEGR), v. 8, n. 3, p. 33-62, jul. 2012.

LESSIG, Lawrence. Against transparency: the perils of openness in government. In: GOTZE, John; PEDERSEN, Christian (ed.). State of the eUnion: Government 2.0 and Onwards. Loomington: AuthorHouse, 2009. LUKENSMEYER, Carolyn; GOLDMAN, Joe; STERN, David. Assessing Public Participation in an Open Government Era: A Review of Federal Agency Plans. Washington: IBM Center for the Business of Government, 2011.

LUNDVALL, Bengt-Åke. Product innovation and user-producer interaction. Aalborg: Aalborg University Press, 1985.

LUNDVALL, Bengt-Åke. Innovation as an interactive process: from user-producer interaction to the national system of innovation. In: DOSI, Giovanni; FREEMAN, Christopher; NELSON, Richard; SILVERBERG, Gerald; SOETE, Luc (ed.). Technical change and economic theory. Londres: Pinter Publisher, 1990. p. 67-98.

LUNDVALL, Bengt-Åke. Políticas de inovação na economia do aprendizado. Parcerias Estratégicas, n. 10, p. 201-218, 2001.

MILANI, Carlos. R. S. O princípio da participação social na gestão de políticas públicas locais: uma análise de experiências latino-americanas e européias. Revista de Administração Pública, v. 42, n. 3, p. 551-579, maio/jun. 2008.

MINAYO, Maria Cecilia. Pesquisa social: teoria, método e criatividade. Petrópolis: Vozes, 2008.

OECD. Organization for Economic Cooperation and Development. Building an open and innovative government for better policies and service delivery. Background document for session Expert meeting. Paris: OECD, 2010.

PAES DE PAULA, Ana P. Administração pública brasileira entre o gerencialismo e a gestão social. Revista de Administração de Empresas, v. 45, n. 1, p. 35-49, abr./jun. 2005.

PORUMBESCU, Gregory; NESHKOVA, Milena; HUNTOON, Meghan. The effects of police performance on agency trustworthiness and citizen participation. Public Management Review, v. 21, n. 2, p. 212-237, 2018.

TORRES, Lars Hasselblad. Citizen sourcing in the public interest. Knowledge Management for Development Journal, v. 3, n. 1, p. 134-145, 2007.

TORRES, Marcelo D. Estado, democracia e administração pública no Brasil. Rio de Janeiro: FGV, 2004. 